\title{
Improvement of Organizational Citizenship Behavior through Personality, Interpersonal Communication, and Organizational Justice
}

\author{
R. Siti Pupu Fauziah*, Thamrin Abdullah, Widodo Sunaryo \\ PostgraduateProgram, Pakuan University, Bogor, Indonesia
}

*Corresponding Author: R. Siti Pupu Fauziah, Postgraduate Program, Pakuan University, Bogor, Indonesia

\begin{abstract}
The purpose of this study is to make efforts to increase teacher organizational citizenship behavior by investigating personality, interpersonal communication and organizational justice. This research employed sequential explanatory, using correlation statistical methods to determine whether personality variables, interpersonal communication and organizational justice have positive relationship with organizational citizenship behavior teachers. SITOREM analysis is used to determine priorities and recommendations for improvements. The study population was Integrated Islamic Elementary School teachers in Bogor city totaling 289, using random methods and Slovin formula calculations, a sample of 168 was selected. The quantitative research results found that all variables had a significant positive relationship with organizational citizenship behavior of teachers. Consistent with the results of quantitative analysis, the results of qualitative data analysis also show that organizational citizenship behavior can be improved through improving teachers' personality, interpersonal communication and organizational justice. The results of the SITOREM analysis show that the organizational citizenship behavior components of teachers, personality, interpersonal communication and teacher organizational justice that need improvement are: 1) trust, 2) openness, 3) appreciation for inspiration, 4) need, 5)altism, 6)sportsmanship, 7)conscientiousness, 8)civic virtue, 9)courtesy. While the components that need to be maintained include: 1) friendliness, 2) selfextraversion, 3) openness to experience, 4) caution, 5) supportive behavior, 6) technical factors, 7) social status, 8) wise, 9) equality, 10) consistency, 11) informative, 12) maintaining ethics and 13) self-esteem.
\end{abstract}

Keywords: SITOREM Analysis, organizational citizenship behavior, personality, communication, interpersonal, organizational justice

\section{INTRODUCTION}

Teachers in educational organizations are individuals who are a core part of the management element. Teachers also become the foremost troops that can move the wheels of educational organizations. Duties and responsibilities of teachers are regulated in the teacher law and lecturer no. 20 of 2005, which are then elaborated on the order of the subsequent invitation to the description of teacher assignments made by foundations and / or school principals. The behavior of the teacher who is able to carry out the main tasks as stated in the job description coupled with an awareness of doing something that he believes can accelerate the achievement of organizational goals which are shown through behaviors such as; help colleagues, get involved in school organizational structures and professional organizations, be tolerant of the situation and always be careful in behaving so as not to cause problems, such behavior in modern management is called organizational citizenship behavior.

Public awareness in helping to educate the nation's life in the city of Bogor lately increasingly visible. This is indicated by the emergence of private elementary schools with various models, one of which is Integrated Islamic Elementary School. The presence of Integrated Islamic Elementary School is a way out for parents who want to send their children to modern islamic-based schools. Data of Integrated Islamic Elementary School students in the Bogor city education office shows the high interest and confidence of the Bogor community in Integrated Islamic Elementary School, therefore conducting research related to Integrated Islamic Elementary School teacher behavior becomes interesting and brings benefits to the progress of basic education especially in the city of Bogor. 
Based on the preliminary survey data, the organizational citizenship behavior of Integrated Islamic Elementary School teachers in Bogor city still needs to be improved. Teachers still tend to carry out tasks limited to the main tasks only. The willingness of teachers to carry out extra activities outside the main task is still low. On the other hand to improve the quality of learning in primary schools, teachers are required to do activities extra

Teacher awareness in carrying out extra-role activities becomes a necessity, it is based on the variety of tasks and responsibilities of teachers. In elementary school teacher activities become more complex because of the age level of students who are still very young. Because of that it becomes interesting to study so that information is obtained about organizational citizenship behavior Integrated Islamic Elementary School teachers in Bogor city and several factors that are suspected to be related include personality, interpersonal communication and organizational justice.

Obtaining information about organizational citizenship behavior teachers and some factors thought to be related to organizational citizenship behavior are expected to be of benefit to improving the quality of education in Bogor city especially primary school education. Based on background, problem identification, and problem limitation. The formulation of the problem in this study are:

- Is there a relationship between personality and organizational citizenship behavior?

- Is there a relationship between interpersonal communication with organizational citizenship behavior?

- Is there a relationship between organizational justice and organizational citizenship behavior?

- Is there a relationship between personality, interpersonal communication and organizational justice together with organizational citizenship behavior?

\section{LITERATURE REVIEW}

\subsection{Organizational Citizenship Behavior}

Fred (2011) suggested that organizational citizenship behavior is the characteristics (properties) of certain personalities contained within the individual, namely the properties of the cooperative, happy to help and attention(caring)of others, and sincerity to work . Organizational citizenship behavior is built from five dimensions: 1. Altruism, i.e. Voluntary actions, such as helping others with work problems, which ultimately benefit the organization (for example, helping coworkers who have fallen behind at work), 2. Conscientiousness, ie working hard and completing work late into the night, 3 , civic virtue, that perform social activities by volunteering(volunteering)to improve the image of the organization, 4. Sportsmanship, which come to feel guilty and responsible for the failure of his team, and 5. Courtesy, namely to understand and feel(empathy)on difficulties faced by the organization or work environment. Organizational citizenship behavior is realized when individuals see that the organization consistently provides support in working, and treats and values them fairly. John (2011) explained that organizational citizenship behavior as an idea to expect employees to work extra has become important because service organizations continue to dominate economic growth.

\subsection{Personality}

According to Gibson (2012) personality is a set of relatively stable characteristics, tendencies, and temperaments that are shaped by inheritance and by significant social, cultural, and environmental factors. Gibson explained about the personality dimensions formulated into The Big Five Personality, namely: 1 . cautious nature, characterized by hard-working, diligent, organized, reliable, and persistent behavior of someone, 2. extraversion, namely the extent to which someone associates, likes to make friends, and resolute compared to quiet, calm, and shy, 3. friendliness, which is a good level of cooperation by sharing trust, warmth, and mutual cooperation, 4. emotional stability, namely the ability of someone to show stress management by staying calm, focused, and trusting self, as opposed to insecurity, anxiety, and depression; and 5. openness to experience, one's scope for attraction to new things, openness, curiosity, and sensitive artistic, as opposed to closed-mindedness. Meanwhile, according to Robbins (2013) personality is the dynamics of the organization between the individual and the psychophysical systems that determine the unique adjustment to their environment.

\subsection{Interpersonal Communication}

According to Burlesson (2010), interpersonal communication is the core of the organization because it creates a structure which then influences what else will be said and done, and by whom. Interpersonal 
communication takes place effectively, then there are several aspects that must be considered by the actors Interpersonal communication, namely: 1. Openness (openness) 2. Empathy (Empathy), 3. Attitudes Support (supportiveness), 4. Positive attitude (positiveness), 5. Equality (equality).

Meanwhile, according to Schermerhon (2011), communication is an interpersonal communication activity in the form of the process of sending and receiving symbols in the form of messages achieved by them. This communication aims to convey messages quickly and briefly through symbols in person. There are four dimensions that affect interpersonal communication, namely self-image, the image of the other party, the physical environment and the social environment.

\subsection{Organizational Justice}

Ivancevich (2012), which explains organizational justice as an area of organizational research that focuses on employees' perceptions and assessments of fairness in the process and decision making of the organization where they are. It can be said that organizational justice reflects the attitude of a leader according to the perception of his subordinates to be fair and objective in making decisions. For example, it involves employee selection and promotion, in assigning and distributing tasks, in conducting performance appraisals, and in determining salary increases, positions, and service fees. The indicators are the factors of lack of fairness in the organization are: performance appraisal is not carried out fairly, setting non-transparent salary increases, promotions and unfair rewards.

Based on the study of theories and concepts related to research variables, namely organizational citizenship behavior, personality, interpersonal communication and organizational justice, the following hypotheses can be formulated:

- There is a positive relationship between personality and organizational citizenship behavior

- There is a positive relationship between interpersonal communication with organizational citizenship behavior

- There is a positive relationship between organizational justice and organizational citizenship behavior

- There is a positive relationship between, personality, interpersonal communication and organizational justice together with organizational citizenship behavior.

\section{Method}

This research was conducted on foundation permanent teachers in thirteen Integrated Islamic Elementary Schools located in Bogor City, West Java province, from July 2018 to December 2018. The method used in this study is a combination research sequential explanatory, which combines quantitative and qualitative research methods sequentially, where in the first stage the research is carried out using quantitative methods and in the second stage is carried out with qualitative methods.

The population used in this study was Integrated Islamic Elementary School teachers with the status of Permanent Teachers of the Foundation in Bogor City totaling 289 teachers from 13 schools. Determination of the sample in this study using the Slovin formula to obtain a total sample of 168 . Sampling using Proportionate Random Sampling.

Data collection techniques in this study used in-depth interviews (in-depth interviews) with Focus Group Discussion, observation, and documentation. After that the data is presented quantitatively and qualitatively, followed by the analysis and discussion of quantitative and qualitative research results using the SITOREM method (Hardhienata, 2007). Based on the results of quantitative and qualitative research analysis through the SITOREM method, conclusions and implications of the research results can be drawn. From the conclusions and implications can be determined suggestions and action plans. As a result of this research mixed methods .

\section{Products And Discussion}

\subsection{Relationship between Personality and Organizational Citizenship Behavior Teachers}

The results of the study showed that there was a significant relationship between personality and organizational citizenship behavior. Based on the results of the research with hypothesis testing, it is known that the correlation coefficient between personality and organizational citizenship behavior 
$\left(\mathrm{r}_{\mathrm{y} 1}\right)$ is 0.306 with the category of having a low relationship. The probability value of $0.000<0.005$ then ho is rejected, it can be concluded that the correlation coefficient is significant. Thus this study confirms that there is a significant relationship between personality and organizational citizenship behavior. The variation in organizational citizenship behavior related to personality is reflected in the coefficient of determination of 0.093 or $9.3 \%$, while the remaining $90.7 \%$ is influenced by other factors.

These results are in line with the theory put forward by Gibson et al. (2012) what is meant by an individual's personality is a set of relatively stable characteristics, tendencies, and temperaments that are shaped by inheritance and by significant social, cultural, and environmental factors. Based on this it can be stated that individuals who have good personalities will increasingly increase their awareness to carry out extra job activities

This study reinforces previous research which has proven that personality has a positive relationship with organizational citizenship behavior teachers. This is evidenced by the results of research from Luthans (2011), between personality and organizational citizenship behavior. The higher one's personality is predicted the higher the organizational citizenship behavior level will be. This means that showing that to be able to improve the organizational citizenship behavior of teachers requires an effort to improve personality.

Similarly, based on qualitative research results of interviews, FGD analysis, observation and documentation in three Integrated Islamic Elementary Schools in Bogor, it can be seen that there is a tendency of a relationship between personality and teacher organizational citizenship behavior. This shows that there is a strengthening of quantitative research on the results of hypothesis testing which states that there is a relationship between personality and organizational citizenship behavior of the teacher with a low correlation coefficient. However, it still shows that increasing personality will increase teacher organizational citizenship behavior.

From the findings obtained in the study through the three stages above, it can be seen that personality is a set of relatively stable characteristics, tendencies, and temperament formed by inheritance and by social factors able to contribute to the increase in organizational citizenship behavior.

\subsection{The Relationship between Interpersonal Communication with Organizational Citizenship Behavior}

The results of the study showed that there was a significant relationship between interpersonal communication with organizational citizenship behavior, meaning that teachers who had high interpersonal communication would have an impact on high organizational citizenship behavior. The strength of the relationship between interpersonal communication with organizational citizenship behavior is reflected in the correlation coefficient of 0.402 with the category of the level of strength of the moderate relationship. Probability value (sig $0,000<0.05$ ), this can be concluded ho is rejected, so it can be interpreted that there is a significant positive relationship between interpersonal communication with organizational citizenship behavior. The variation in organizational citizenship behavior related to interpersonal communication is reflected in the coefficient of determination 0.161 or $16.1 \%$, while the remaining $83.9 \%$ is influenced by other factors.

These results are in line with the theory put forward by Colquit (2011) referred to as interpersonal communication refers to communication in two directions, where two individuals share roles as senders and recipients who are interconnected through mutually beneficial activities. Thus individuals who have good interpersonal communication will increasingly increase their awareness to carry out extra job activities organizational citizenship behavior.

The conclusions of this study reinforce the results of previous studies have proven that interpersonal communication has a positive relationship with organizational citizenship behavior teachers, this is evidenced by the results of research from Ince (2011), between interpersonal communication with organizational citizenship behavior. The higher the interpersonal communication is predicted to be the higher the organizational citizenship behavior level. This means it shows that to be able to improve organizational citizenship behavior the teacher needs an effort to improve interpersonal communication.

Likewise, based on the qualitative research results of the analysis of interviews, FGD, observation and documentation in three Integrated Islamic Elementary Schools in Bogor, it can be seen that there is a 
tendency for a relationship between interpersonal communication with organizational citizenship behavior teachers. This shows that there is a strengthening of quantitative research on the results of hypothesis testing which states that there is a relationship between interpersonal communication and organizational citizenship behavior teachers with moderate correlation coefficients. However, it still shows that increasing interpersonal communication will strengthen teacher organizational citizenship behavior.

From the findings obtained in the research through the three stages above, it can be seen that interpersonal communication is an activity of reciprocating and receiving reciprocal messages carried out by individuals who have a close relationship to achieve the desired goals within the organization able to contribute to the improvement of organizational citizenship behavior.

\subsection{Relationship between Organizational Justice and Organizational Citizenship Behavior}

The results of research that show there is a significant relationship between organizational justice and organizational citizenship behavior means that teachers who have high organizational justice will have a high impact on organizational citizenship behavior. The strength of the relationship between organizational justice and organizational citizenship behavior is reflected in the correlation coefficient of 0.217 with a weak relationship level category. Probability value (sig $0.005<0.05$ ), it can be concluded that Ho is rejected, so it can be interpreted that there is a significant positive relationship between organizational justice and organizational citizenship behavior. The diversity in organizational citizenship behavior related to organizational justice is reflected in the coefficient of determination of 0.047 or $4.7 \%$, while the remaining $95.3 \%$ is influenced by other factors.

This result is in line with the theory put forward by Stephen (2013) what is meant by organizational justice is the whole perception of justice in the workplace that is built from distributive, procedural and interactional justice. Thus individuals who have good organizational justice will increasingly increase their awareness to carry out extra job activities organizational citizenship behavior.

Likewise, based on the qualitative research results of the analysis of interviews, FGDs, observations and documentation in three Integrated Islamic Elementary Schools in Bogor, it can be seen that there is a tendency for a relationship between organizational justice and organizational citizenship behavior teachers. This shows that there is a strengthening of quantitative research on the results of hypothesis testing which states that there is a relationship between organizational justice and organizational citizenship behavior teachers with low correlation coefficients. However, it still shows that increasing organizational justice will strengthen teacher organizational citizenship behavior.

From the findings obtained in the research through the three stages above it can be seen that organizational justice is one's perception of the organization or leadership in treating themselves fairly capable of contributing to the improvement of organizational citizenship behavior.

\subsection{Relationship between Personality, Interpersonal Communication and Organizational Justice with Organizational Citizenship Behavior}

The results of the study showed a significant positive relationship between personality, interpersonal communication and organizational justice with organizational citizenship behavior. Based on the results of the study obtained the correlation coefficient value between the personality, interpersonal communication and organizational justice with organizational citizenship behavior $\left(\mathrm{r}_{\mathrm{y} 123}\right)$ of 0.414 with a strong enough category, with a probability value (sig) $0,000<0.005$, then Ho is rejected meaning that there is a significant relationship between personalities, interpersonal communication and organizational justice with organizational citizenship behavior. Thus this study confirms that there is a significant positive relationship between personality, interpersonal communication and organizational justice together with organizational citizenship behavior.

The results of this study get the equation $\hat{\mathrm{Y}}=48.312+0.154 \mathrm{X} 1+0.322 \mathrm{X} 2+0.002 \mathrm{X} 3$ can be used to predict organizational citizenship behavior based on personality scores, interpersonal communication and organizational justice. This means that the equation can predict each increase in 1 personality score, interpersonal communication and organizational justice together will increase organizational citizenship behavior by 0.154 times for personality variables, 0322 times for interpersonal communication variables and 0.002 times for organizational justice variables at a constant 48.312. 
The findings obtained in this study identify that if the individual has a high personality value in the ability to convey good interpersonal communication messages and perceptions about organizational behavior or leadership towards them of high value then such conditions will encourage and or provide support to individuals to carry out activities outside main task activities and functions without being directly related to the prevailing formal reward system (organizational citizenship behavior) in other words personality, interpersonal communication and organizational justice can jointly improve teacher organizational citizenship behavior.

SITOREM Analysis is summarized below.

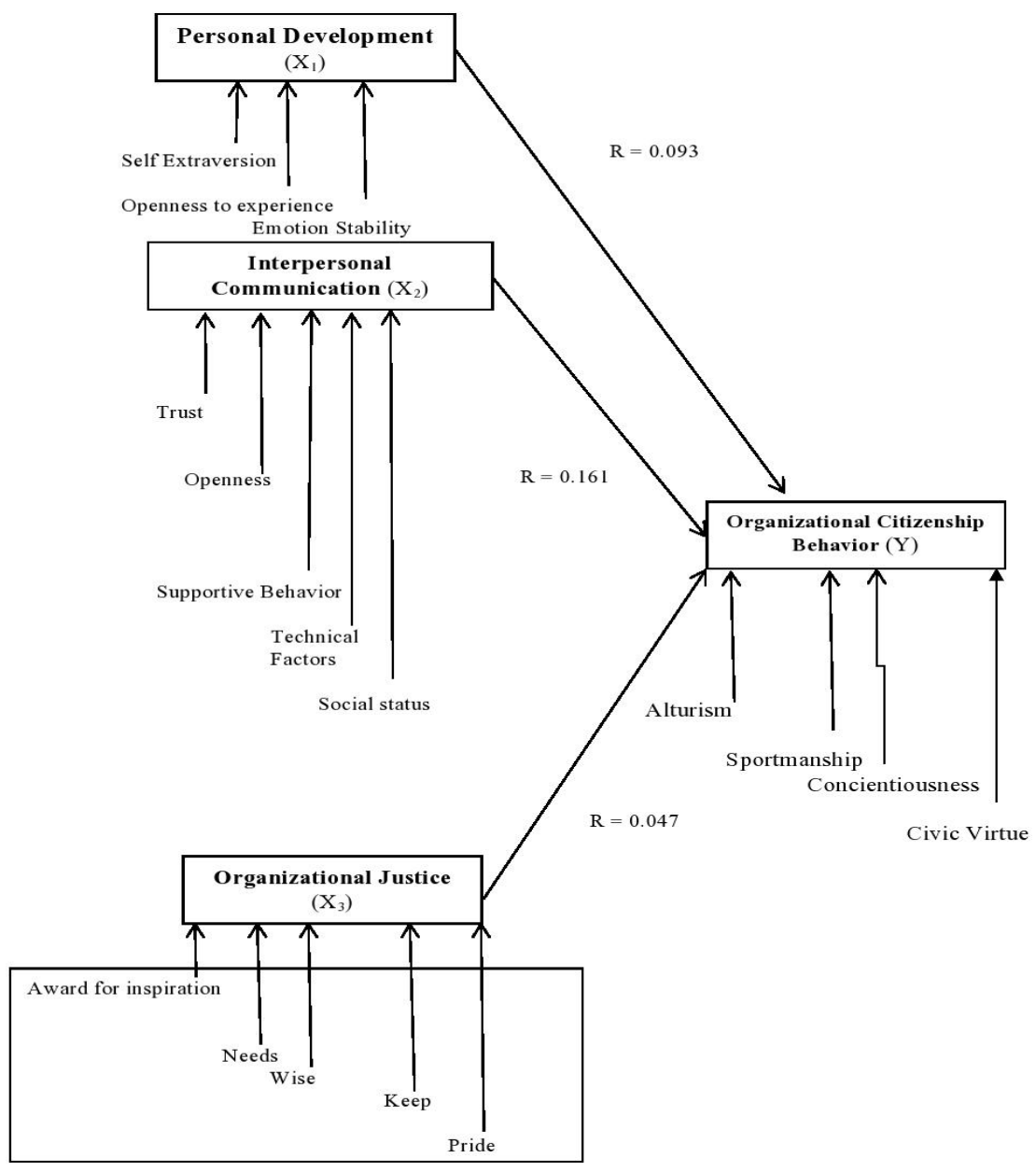

Figure1: SITOREM Analysis

\section{CONCLUSION}

Based on the results of the quantitative research stage, namely the analysis of data processing results, statistical calculations, hypothesis testing and discussion of research results regarding the relationship between personality, interpersonal communication and organizational justice with organizational citizenship behavior teachers in Integrated Islamic Elementary Schools throughout Bogor City, and based on qualitative research, namely results FGDs, interviews, and observations can be seen that this study has found an effort to improve teacher organizational citizenship behavior through identifying the strength of the relationship between research variables, namely:

- There is a positive relationship between personality and teacher organizational citizenship behavior with a low level of correlation coefficient. The results of qualitative research indicate a tendency for a relationship between personality and organizational citizenship behavior. SITOREM analysis shows that there are no indicators that need to be improved. Based on the three stages of the research, it can be seen that personality is a set of relatively stable characteristics, tendencies, and temperaments formed by inheritance and by social factors able to contribute to the improvement of organizational citizenship behavior. 
- There is a positive relationship between interpersonal communication with organizational citizenship behavior teachers with a moderate level of correlation coefficient. Qualitative research results indicate a tendency between interpersonal communication with organizational citizenship behavior and SITOREM analysis states that there are two indicators namely trust and openness that must be improved. Based on the three stages of the research it can be seen that interpersonal communication is an activity of reciprocating and receiving reciprocal messages carried out by individuals who have a close relationship to achieve the desired goals within the organization able to contribute to the improvement of organizational citizenship behavior.

- There is a positive relationship between organizational justice and organizational citizenship behavior teachers with low correlation coefficient levels. The results of qualitative research indicate a tendency between organizational justice and organizational citizenship behavior. SITOREM analysis states that there are two indicators that must be improved, namely appreciation for inspiration and needs. Based on the three stages of the research it can be seen that organizational justice is a person's perception of the organization or leadership in treating themselves fairly able to contribute to the improvement of organizational citizenship behavior.

- There is a positive relationship between personality, interpersonal communication, and organizational justice together with organizational citizenship behavior teachers with a moderate level of correlation coefficient. Qualitative research results indicate a tendency between personality, interpersonal communication and organizational justice together with organizational citizenship behavior. Based on the stages of the research it can be seen that personality, interpersonal communication and organizational justice together can contribute to the improvement of organizational citizenship behavior.

\section{REFERENCES}

[1] Burleson, BR (2010). The nature of interpersonal communication. CR Berger, M. Roloff, \& Dr. RoskosEwoldsen, The Handbook of Communication Science.

[2] Colquitt, J., Lepine, JA, Wesson, MJ, \& Gellatly, IR (2011). Organizational behavior: Improving performance and commitment in the workplace (Vol. 375). New York, NY: McGraw-Hill Irwin.

[3] Devito, JA (2009). The interpersonal communication book: International edition. Publ .: Ally \& Bacon.

[4] Gibson, J.L, Ivancevich, J.M, \&Donnelly, J.(2009): Organizations. Behavior, Structure, and Processes. Prentice Hall, New York.

[5] Hardhienata, S. (2017). The development of scientific identification theory to conduct research operations in management education. In IOP Conference Series: Materials Science and Engineering (Vol. 166, No. 1, p. 012007). IOP Publishing.

[6] Ince, M., \& Gül, H. (2011). The effect of employees' perceptions of organizational justice on organizational citizenship behavior: An application in Turkish public institutions. International Journal of Business and Management, 6(6), 134.

[7] Luthans, F., Youssef, CM, \& Rawski, SL (2011). A tale of two paradigms: The impact of psychological capital and reinforcing feedback on problem solving and innovation. Journal of Organizational Behavior Management, 31(4), 333-350.

[8] McShane, SL, \& Von Glinow, MAY (2010). Workplace emotions, attitudes, and stress. Organizational Behavior, 5 .

[9] Robbins, SP and Timothy A. Judge. 2013. Organizational Behavior.

[10] Robbins, SP, Judge, TA, \& Millett, B. (2015). OB: the essentials. Pearson Higher Education AU.

[11] Schermerhorn Jr., JR (2011). HUNT, James G. OSBORN, Richard N. Fundamentos de Comportamento Organizacional. 2ed. Porto Alegre: Bookman.

Citation: R. Siti Pupu Fauziah, et.al. "Improvement of Organizational Citizenship Behavior through Personality, Interpersonal Communication, and Organizational Justice" International Journal of Managerial Studies and Research (IJMSR), vol 7, no. 12, 2019, pp. 47-53. doi: http://dx.doi.org/10.20431/2349-0349.0712007.

Copyright: ( $) 2019$ Authors. This is an open-access article distributed under the terms of the Creative Commons Attribution License, which permits unrestricted use, distribution, and reproduction in any medium, provided the original author and source are credited. 